\title{
Radiosynovectomy in rheumatic diseases
}

\begin{abstract}
Radiosynovectomy (RS) is a method of local treatment of chronic inflammatory joint diseases, alternative to surgical synovectomy. This method is based on an anti-proliferative and anti-inflammatory character of ionizing radiation. RS is very successful method in case of inefficiency of standard therapies of chronic inflammatory joint diseases and intraarticular injection of glucocorticoids (GCS). RS for chronic inflammatory joint diseases is an effective treatment. RS causes on synovium function reduction of pain, swelling and improves joint mobility-this effect was confirmed in ultrasonography examinations after procedure.
\end{abstract}

Volume 5 Issue 6 - 2016

\author{
Margaret Wislowska \\ Central Clinical Hospital MSW, Poland
}

Correspondence: Margaret Wislowska, Central Clinical Hospital MSW, ul Wolowska, 137 02-507, Warszawa, Poland, Tel 48-609-458-447, Email mwislowska@wp.pl

Received: July 20, 2016 | Published: October 04, 2016

Keywords: Radiosynovectomy, Chronic inflammatory joint diseases, Rheumatoid arthritis, Pigmented villonodular synovitis, Hemophilic arthropathy, Synovium, Ionizing radiation

\section{Introduction}

Radiosynovectomy (RS) is a method of topical treatment of chronic arthritis, using the antiproliferative and anti-inflammatory effects of ionizing radiation. Colloidal particles of the radionuclide are phagocytosed by macrophages of inflamed synovium. Beta radiation emitted by the radiopharmaceutical causes to coagulative necrosis of synoviocytes, which absorbed the drug. After treatment there is a significant reduction of the number and size of the villi of the synovium, and also the reduction of the infiltration of synovial mononuclear cells which caused progressive, persisting fibrosis. RS admits to restore the physiological structure and properties of the synovium. If the therapy was applied early in the disease, it restrains the destruction of joint structures, and allows returning full-function of joints.

The response to treatment is obtained with a delay-usually one month to six months after the procedure and may be preceded by a transient severity of inflammation of the synovium and pain. The reduction of pain usually occurs 1 - 3 weeks after RS, and the possible lack of response to treatment can be determined after 6 weeks. Another unsuccessful application of radioisotope after 6 months indicates the ineffectiveness of this therapy. The beneficial effects of treatment can be long-lasting.

RS has been used in the treatment of patients with chronic inflammatory diseases of the musculoskeletal system such as rheumatoid arthritis, ankylosing spondylitis, psoriatic arthritis, reactive arthritis and arthritis associated with chronic non-specific inflammatory bowel disease, gout, chondrocalcinosis, Lyme disease, Behcet's disease, hemophilic arthropathy, pigmented villonodular synovitis, undifferentiated arthritis, recurrent effusions after total knee replacement and osteoarthritis - mainly knee osteoarthritis and crystal synovitis. ${ }^{1}$ It is an alternative method to surgical synovectomy and intraarticular injection of GCS. Compared with surgery, RS is a minimally invasive procedure without anesthesia, prolonged immobilization and long rehabilitation. It also requires less financial costs. This is a repeatable procedure and gives long-lasting beneficial effects. ${ }^{2}$ RS is a promising method for the treatment of rheumatic diseases.

The numerous papers show significant improvement of efficacy of RS. ${ }^{3-10}$ This method was first used in 1952 in patients with rheumatoid arthritis. ${ }^{11} \mathrm{RS}$ is radionuclide therapy of joint synovitis by intraarticular injection of $90 \mathrm{Y}$ silicate / citrate or $186 \mathrm{Re}$ sulphide or $169 \mathrm{Er}$ citrate $^{1}$ The indication to the therapy are the findings an increase uptake in the blood pool phase (which is the main sign of arthritis) by two-phase bone scintigraphy using technetium -99m-methylene diphosphonate (99mTc-MDP). The success rate of RS is $65-80 \%$.

\section{The radiopharmaceuticals used in this method'}

$90 \mathrm{Y}$ emits a beta particle with a maximum energy of $2.27 \mathrm{MeV}$, with the mean energy of $0.935 \mathrm{MeV}$ and an average soft-tissue range of $3.6 \mathrm{~mm}$. The physical half-life is 2.7 days. 186Re emits a beta particle with a maximum energy of $1.07 \mathrm{MeV}$, with the mean energy of $0.349 \mathrm{MeV}$, an average soft-tissue range of $1.1 \mathrm{~mm}$ and a $9 \%$ abundant gamma emission with a photo peak of $0.137 \mathrm{MeV}$. The physical halflife is 3.7 days. - $169 \mathrm{Er}$ emits a beta particle with a maximum energy of $0.34 \mathrm{MeV}$, with the mean energy of $0.099 \mathrm{MeV}$ and an average softtissue range of $0.3 \mathrm{~mm}$. The physical half-life is 9.4 days.

Contraindications for radiosynovectomy are pregnancy and breastfeeding period, local infection, massive hemarthroses and ruptured Baker's cyst.

\section{Potential complications/side effects after radiosynovectomy are listed below ${ }^{12}$}

I. Local, acute inflammation of the synovium in the treated joint, induced by the administration of radiocolloid, overlaying the present chronic/subacute inflammation (occurring frequently in approximately $40-50 \%$ of patients - with varying degrees of severity).

II. Intraarticular bleeding (hemarthrosis, most often in patients with severe hemophilia and inhibitors present).

III. Contamination of the skin with radiocolloid during removal of the needle puncture (rare).

IV. Radiocolloid leakage outside the joint puncture through a hole in the joint capsule or a ruptured bursa, occurring mostly in case of the rupture of Baker's cysts and potential causing irritation or necrosis of the tissue surrounding.

\section{Skin / joint infection following RS.}

The therapy is well-tolerated with a low rate of side effects. In respect of the specific uptake of particles in the synovium and short range of beta radiation, the radiation exposure outside the joint is very low. RS with $90 \mathrm{Y}$ and $186 \mathrm{Re}$ have been shown to reduce the number of bleeding episodes, relieve articular pain, improve the range of joint 
flexion and extension, muscle strength in flexion and extension, and normalize the thickness of the synovium in patients with chronic hemophilic synovitis. ${ }^{13}$ Matryba et al. ${ }^{3}$ evaluated the effect of RS of RA patients and observed the reduction of swelling and joint pain, which occurred in $43.5 \%$ of patients. These therapeutic effects of RS were similar to earlier observations ${ }^{14,15}$ and the best effects were observed after RS of PIP joints of the fingers - the reduction of swelling occurred in all patients. After RS of knee joints- an improvement was observed in $68.7 \%$ of patients. ${ }^{3}$ This effectiveness is best documented for rheumatoid arthritis and hemophilic arthritis. In another group of patients treated with osteoarthritis, hemophilic arthropathy, undifferentiated arthritis, psoriatic arthritis, the reduction of swelling was observed in $50 \%$ of patients, and the reduction of pain in $43.3 \%$ of cases $^{3}$ these results are comparable with the results of the paper of Kroger et al., ${ }^{4}$ and other studies in which RS achieved good results in about $40 \%$ to $80 \%$ of patients. ${ }^{5,6}$ Jahangier et al. ${ }^{7}$ Confirmed significant improvement in patients who underwent RS due to psoriatic arthritis and in patients with ankylosing spondylitis Gazda et al. ${ }^{8}$ Demonstrated significant clinical, biochemical and ultrasound improvement in $66 \%$ of children who had undergone RS due to juvenile idiopathic arthritis. In pigmented villonodular synovitis RS is particularly useful as an adjuvant therapy after the surgical/arthroscopic removal of the synovium. ${ }^{9}$ In the treatment of arthritis resulting from Lyme disease and crystal-induced arthritis RS was also efficient. ${ }^{10}$

The assessment of a significant efficacy of RS, based on the result of the ultrasound examinations, that determines the severity of synovitis before and after treatment, was confirmed by the existing reports. ${ }^{16-19}$

\section{Acknowledgments}

None.

\section{Conflicts of interest}

None.

\section{References}

1. Clunie G, Fischer M. EANM Procedure Guidelines for Radiosynovectomy Eur J Nucl Med. 2003;30(3):12-16.

2. Knut L. Radiosynovectomy in the Therapeutic Management of Arthritis World J Nucl Med. 2015;14(1):10-15.

3. Matryba M, Ćwikła JB, Wisłowska M. Ocena skuteczności zabiegu radiosynowektomii u chorych z przewlekłymi wysiękowymi zapaleniami stawów. Problemy Lekarskie. 2011;46:12-18.

4. Kröger S, Sawula JA, Klutmann S, et al. Efficacy of radiation synovectomy in degenerative inflammatory and chronic inflammatory joint diseases. Nuklearmedizin. 1999;38(7):279-284.
5. Farahati J, Schulz G, Wendler J, et al. Multivariate analysis of factors influencing the effect of radiosynovectomy. Nuklearmedizin. 2002;41(2):114-119.

6. Siegel HJ, Luck VJ, Siegel ME. Phosphate-32 colloid radiosynovectomy in hemophilia: outcome of 125 procedures. Clin Orthop Rel Res. 2001;392:409-417.

7. Jahangier ZN, Moolenburgh JD, JW Jacobs, et al. The effect of radiation synovectomy in patients with persistent arthritis: a prospective study. Clin Exp Rheumatol. 2001;19(4):417-424.

8. Gazda A, Królicki L, Gietka P, et al. Radionuclide synovectomy in children with juvenile idiopathic arthritis-own observations. Rheumatology. 2011;49:156-161.

9. Nassar WA, Bassiony AA, Elghazaly HA. Treatment of diffuse pigmented villonodular synovitis of the knee with combined surgical and radiosynovectomy. 2009;HSS,J5(1):19-23.

10. Kampen WU, Voth M, J Pinkert, et al. Therapeutic status of radiosynoviorthesis of the knee with yttrium [90Y] colloid in rheumatoid arthritis and related Indications. Rheumatology (Oxford). 2007;46(1):16-24.

11. Fellinger K, Schmid J. Local therapy of rheumatic diseases. Wien Z Inn Med. 1952;33(9):351-363.

12. Kisielinski K, Bremer D, Knutsen A, et al. Complications Following radiosynoviorthesis in osteoarthritis and arthroplasty: osteone $\neg$ crosis and intra-articular infection. Joint Bone Spine. 2010;77(3):252-257.

13. De la Corte-Rodriguez H, Rodriguez-Merchan EC, Jimenez-Yuste V. Radiosynovectomy in patients with chronic haemophilic synovitis: when is more than one injection necessary? Eur J Haematol. 2011;86(5):430-435.

14. Zwolak R. Radiosynowiorteza w codziennej praktyce. Przeglad Reumatologiczny. 2008;3:1-2.

15. Troise Rioda W, Nervetti A, Ugolotti G, et al. Knee radiosynovectomy with Y90 in patients with rheumatoid arthritis: our experiences. Reumatismo. 2008;60(3):206-211.

16. Gratz S, Gobel D, Behr TM, et al. Correlation between radiation dose, synovial thikness and efficacy of radiosynoviorthesis. Rheumotol. 1999;26(6):1242-1249.

17. Li P, Yu J, Chen G, et al. Applied radioactivity in radiation synovectomy with [188 Re] rhenium sulfide suspension. Nucl Med Commun. 2006;27(8):603-609.

18. Shin K, Lee JC, Choi HJ, et al. Radiation synovectomy using $188 \mathrm{Re}-$ tin colloid improves knee synovitis as shown by MRI in refractory rheumatoid arthritis. Nucl Med Commun. 2007;28(4):239-244.

19. Pirich C, Schwameis E, Bernecker P, et al. Influence of radiation synovectomy on articular cartilage, synovial thickness and enhancement as evidenced by MRI in patients with chronic synovitis. $\mathrm{J} \mathrm{Nucl} \mathrm{Med}$. 1999;40:1277-1284 